\section{Research Square}

Preprints are preliminary reports that have not undergone peer review.

They should not be considered conclusive, used to inform clinical practice, or referenced by the media as validated information.

\title{
The Influence of Mindfulness Meditation Versus CBT for Anxiety on Emotional Distress and Attitudes Towards Seeking Mental Health Treatment
}

\author{
Daniela Aisenberg-Shafran ( $\nabla$ danielaa@ruppin.ac.il ) \\ Ruppin Academic Center \\ Liav Shturm \\ Ruppin Academic Center
}

\section{Research Article}

Keywords: MBIS, CBT, depression, anxiety, treatment, attitudes

Posted Date: November 30th, 2021

DOI: https://doi.org/10.21203/rs.3.rs-1071334/v1

License: (c) (i) This work is licensed under a Creative Commons Attribution 4.0 International License. Read Full License 


\section{Abstract}

Older adults often avoid seeking psychological treatment, challenging their ability to adaptively deal with anxiety, stress and depression. The aim of the current study was to compare the effects of a mindfulness intervention vs. cognitive-behavioral-therapy (CBT) on measures of emotional distress and attitudes towards seeking mental-health treatment among older adults.

Twenty-four seniors were assigned to: 1) MBIS (Mindfulness-Based Intervention for Seniors); and 2) CBT for anxiety, or to a care-as-usual control group. Attitudes towards seeking psychological treatment, levels of depression, anxiety and worry were measured before and after the interventions.

Following the intervention, participants more positively addressed the possibility of utilizing psychological treatment, while no changes were observed in the control group. Interestingly, levels of worry improved only in the MBIS group, and anxiety levels only improved in the CBT group.

It seems that attending cognitive group interventions are effective to their focus and positively impact attitudes towards psychological treatment.

\section{Introduction}

Aging can be experienced as a complicated and challenging process, especially considering the increased exposure and proximity to death alongside the physical, emotional and cognitive decline characteristic of old age (as will be described later in this paper). This considered, there is great need for interventions that can improve the elderly population's quality of life and ease its pain. Such interventions must be made accessible, as this age group poses extreme difficulty in utilizing them (Kessler et al., 2015). The current study will examine the influence of a Mindfulness-Based Intervention for Seniors (MBIS) and a Cognitive Behavioral Intervention (CBT) on various psychological measures and on senior attitudes towards seeking mental health treatment.

Mindfulness is defined in a variety of ways, all of which are sourced in the Buddhist tradition. The most well accepted Western definition defines mindfulness as the maintenance of prolonged attention on human experiences (i.e. thoughts, emotions, bodily sensations, etc.) in the present, "from moment to moment" and in an accepting, non-judgmental manner (Kabat-Zinn, 2013). This definition incorporates three components that are also referenced in the majority of Buddhist literature on the topic of mindfulness. These three components are: 1) Attentive awareness; 2) Current experience; and 3) Acceptance.

The past 30 years is marked by an accumulation of literature that points to the significant advantages of meditation on a variety of factors related to mental and physical health (Chiesa \& Seretti, 2009). The first successful studies on mindfulness examined patients that suffer from chronic pain and tension. These first studies encouraged the development of Mindfulness-Based Stress Reduction (MBSR) for this population (Kabat-Zinn, 1990). At a later stage, Mindfulness-Based Cognitive Therapy (MBCT) was developed. MBCT is a therapeutic intervention based on MBSR but, differs from it in its focus on depression and in its use of a dominant psycho-educational feature that focuses on the prevention of relapse (Segal, Teasdale \& Williams, 2002). These two standard interventions include one weekly session that averages 2.5 hours for eight weeks. A meta-analysis of 64 studies found that mindfulness-based interventions are effective in coping with chronic pain, Fibromyalgia, Coronary Artery diseases, cancer, anxiety disorders, depression, and contextual stressors (Grossman et al., 2004).

There are a number of theoretical underpinnings that may explain the mechanism behind the psychological-therapeutic effect that accompanies methodological practice of mindfulness. These theoretical explanations have a wide range of empirical support from metaanalyses on mediation research (Gu et al., 2015). One theoretical explanation suggests that the very ability to focus attention and respond with acceptance and non-judgment towards life experiences independently improves attentional and self-regulatory capacities. Another explanation is that the suggestion to accept any and all thoughts and emotions without avoidance encourages a diminished usage of repression and assists in arousing autobiographical memories from specific places and time, both of which are tremendously valuable to mental health treatment. A third theoretical explanation suggests that mindfulness helps in diminishing negative ruminative thinking by bringing negative thoughts to consciousness and, then, decreasing reactivity to them. Mindfulness also appears to influence emotional and cognitive flexibility as well as changes to self-perception. The aforementioned considered, it seems that the therapeutic mechanisms behind meditation are not meant to directly eradicate the psychological or physical symptom but, rather, to strengthen the capacity to cope with it (Shapiro et al., 2006). Neurological findings show that the practice of mindfulness is associated with neuroplastic changes in the Anterior Cingulate Cortex (ACC), Insula, Temporoparietal Junction (TPJ), the frontal-limbic system and the default mode network. These areas were found to contribute to an improvement in emotion regulation and present further support for the efficacy of mindfulness (Holzel et al., 2011).

The aforementioned research literature encouraged the current study, which aims to expand our understanding and knowledge of health in old age as well as to emphasize its importance. The senior population is continuously challenged with maintaining and advancing its wellbeing. 
Data from a U.S. Census study that included 12,312 adults, 64 years of age or older, suggests that $11.4 \%$ of older adults cope with anxiety disorders while $6.8 \%$ cope with emotion disorders, all of which met clinical criteria for diagnosis (Reynold et al., 2015). It is important to note that by including symptoms that do not meet the clinical criteria for diagnosis, the percentage of depression and anxiety increases significantly in the elderly, more than in any other age group (Jorm, 2000). Seniors are at an increased risk for traumatic life experiences and loss (i.e. the death of family members and close friends, decline in cognitive functioning, decline in physical functioning, loneliness), both of which have the potential to significantly and negatively impact their daily routine and encourage anxiety and depression and a plethora of other issues and illnesses (Lomas et al., 2015). Further, untreated emotional distress, anxiety and depression progressively worsen with age (Rodda, Walker \& Carter, 2011). Neimeyer and Holland's (2015) paper on bereavement in old age suggests that in the first year of losing a spouse, $12 \%$ cope with Generalized Anxiety Disorder (GAD). In addition, elderly individuals who experience complex bereavement disorder (17.2\%) tend to display anxiety symptoms that meet criteria for an anxiety disorder. Anxiety and decline of one's physical state are associated with one another in a cyclic fashion such, that anxiety encourages avoidance behavior which encourages muscle weakening and pathology to the muscular and skeletal systems which, then, encourages further atrophy (Skelton \& Muhaidat, 2015). A meta-analysis on loneliness in old age (Kitzmuller et al., 2018) pinpoints general themes that explain and detail the experience of loneliness in old age: the loss of significant interpersonal relationships, the negative influence of loneliness on self-perceptions, and negative emotions associated with loneliness such as, anxiety, sadness, and anger. These themes were found to be reciprocally associated with one another. The bio-psycho-social model (Garroway \& Rybarczyk, 2015) describes the mutual influence of the physical, mental and social state of the individual, positing a more significant interrelation in the elderly than in younger individuals. This model suggests that a chronically stressful environment significantly increases vulnerability to illness and the loss of functional capacities, which, in turn, increases anxiety and a sense of helplessness. Another example relates to chronic illness in old age like anxiety, depression and bi-polar disorder, which are all associated with higher risk for suicidal behavior in old age. In accordance with Garroway \& Rybarczyk's model, depression and anxiety were found to encourage cognitive biases that act as psychological barriers that potentially delay or prevent adaptive behavior in response to challenges in old age. For example, the use of a walking stick may be avoided as it symbolizes a worsened physical state and some level of submission - symbolic threats to one's identity and ego.

The increased vulnerability for emotional distress in old age emphases the need for successful and short-term interventions that can quickly improve the health and quality of life for seniors. A study on elderly participants, that examined the efficacy of a brief, 4-week, behavioral intervention, found a significant improvement in various psychological and cognitive measures (Noice \& Staines, 2004). Another study examined a brief, 4-week behavioral intervention intended to assist seniors with chronic sleep difficulties and found a significant improvement in the sleep quality of the participants in the intervention group (Buysee et al., 2011).

Few research studies have examined the influence of mindfulness on measures of anxiety and depression in the elderly. For example, a metaanalysis that examined existing mindfulness-based interventions and their influence on mental and physical wellbeing in the elderly only included four studies (Geiger et al., 2016). Two of these studies examined the influence of a standard, 8-week MBCT intervention and found a decrease in measures of anxiety and depression with a moderate-to-high effect size (Splevins et al., 2009; Foulk et al., 2014). The other two studies examined a standard, 8-week MBSR intervention and found a decrease in measures of anxiety and depression with a high effect size (Young \& Baime, 2010; Lenze et al., 2014). None of these four studies compared the experimental group with a control group that underwent a different treatment intervention, while three of the studies made no comparison between the experimental group and a control group. A MBCT study on elderly individuals (Helmes \& Ward, 2015), which incorporated an activity-based control treatment group and whose experimental group was exposed to a shortened intervention (1.5 hours), also found a decrease in measures of anxiety and with a high effect size. Although the efficacy displayed by these interventions, the various interventions are characterized by high attrition rates (about 15\%). Gender (men end participation more than women), few years of education, an expectation for quick change, and high levels of distress (Nam \& Toneatto, 2016; Marjani, 2017) seem to be the primary causes for these attrition rates. A solution for these high rates of attrition was suggested in a metaanalyses performed by Carmody \& Baer (2009), which examined 25 studies that implemented mindfulness-based interventions with different lengths and in different age groups. The researchers believe that the number of sessions made attendance difficult while they did not find any evidence to suggest that shortened versions of mindfulness interventions are less effective than the standard intervention in diminishing emotional distress. These researchers, therefore, suggest shortening mindfulness interventions to make them more accessible for population groups (i.e. the elderly) that have a difficulty committing to standard interventions.

Another popular intervention for depression and anxiety in the elderly is CBT. As it's name suggests, CBT aims at changing the thoughts and behaviors that cause distress to the patient, all while cultivating thoughts and behaviors that are more effective for the patient. The basic assumption in CBT is that emotional distress is the result of how individuals perceive and interpret their reality and, not necessarily, a result of objective reality. CBT, therefore, places significant emphasis on solving current issues (Byrne, 2013). A literature review combined a number of meta-analyses that examined the efficacy of CBT for anxiety and depression in the elderly and found significant efficacy, as displayed by the higher than average effect sizes for CBT (Satre, Knight \& David, 2006). 
It is important to note that alongside the many benefits of these interventions and the many and varied solutions mental health treatment offers the elderly, this population seeks mental health services less than younger age groups (Kessler et al., 2015). Three factors were found to have the most significant impact on attitudes towards seeking treatment among the elderly. These include: 1) their perception of their aging process; 2) their perception of psychologists; and 3) their perception of social support. Further, stigma - a distinguishing characteristic or trait that disqualifies those that carry it from full social acceptance (Goffman, 1963) - has been found to be one of the central factors for why the elderly avoid seeking mental health treatment (Conner et al., 2010). Considering the above, there is a need for short-term interventions that will adaptively change the cognitive perceptions associated with attitudes towards seeking mental health treatment. This should contribute to an increase in elderly utilization of therapy - private or group therapy. As stated earlier in this introduction, mindfulness-based interventions help individuals accept their current thoughts and emotions in a non-judgmental manner. In this way, the mindfulness-practicing individual observes or contemplates his thoughts instead of developing a reactive response to them. Introspection helps create a mental and emotional distance between the individual and his thoughts, which enables, amongst other things, a more flexible way of approaching one's thoughts even non-adaptive perceptions.

The current study aims at adding two dimensions to existing literature: 1) Establish support for a short-term mindfulness-based intervention for seniors as effective in diminishing levels of anxiety and depression in old-age and as encouraging utilization of mental health treatment; 2) A comparison of this treatment to another treatment intervention (CBT). To the best of our knowledge, there is no existing research that examines the influence of mindfulness on anxiety in the elderly with an effective control group that isolates the effects of diaphragmatic breathing (a potential confounding variable). Mindfulness-based interventions that have been effective in reducing anxiety and stress in the elderly often include a breathing exercise. Further, behavioral relaxation techniques such as, diaphragmatic breathing, have been shown to be most effective in reducing anxiety and stress in the elderly (Lenze et al., 2014). For this reason it is important to isolate and examine the unique attentional component of mindfulness-based interventions. Second, and to the best of our knowledge, there is no existing research that has examined the influence of mindfulness on attitudes towards seeking mental health treatment among the elderly.

Research Hypotheses:

1. An interaction between group and time in the measure of emotional distress will be found such, that the MBIS and the CBT groups will significantly improve in their measures of anxiety and depression when compared to the control group.

2. An interaction between group and time in the measure of attitudes towards seeking mental health treatment will be found such, that the MBIS group will significantly improve its attitudes towards seeking mental health treatment when compared to the control group. We did not hypothesize the direction of the CBT group in this interaction.

\section{Method}

\section{Participants}

24 elderly adults with normative functioning participated in this study. All participants were recruited from a senior's club in the center of Israel (22 women; $M=73.12 ; S D=5.67)$. The participants were allocated into three groups (MBIS, CBT, care-as-usual control group), totaling 8 participants in each group. 12 participants began the MBIS $8 * 1$ course, three of whom cancelled their participation and one participant ended her participation after the second session (33\% attrition rate). 12 participants began the CBT $8 * 1$ course, two of whom cancelled their participation, one participant ended her participation after the second session and another participant ended her participation after the third session (33\% attrition rate). Reasons for attrition were: an unexpected move, difficulty committing, lack of interest, and a decline in physicalmental health. A make-up session was provided to participants who missed the first session.

\section{Procedure}

At the recruitment stage of this study an informational session took place during which a brief and general explanation was provided, participation was encouraged and, at its culmination, those interested signed up. An additional session was set for the individuals that chose to participate in the study. At this additional session prospective participants signed informed consent forms for participation in the study, completed a demographic questionnaire, an attitudes towards seeking mental health treatment questionnaire, and a number of questionnaires that measure emotional distress (see Tools). Afterwards, the participants were randomly allocated to one of two intervention groups: 1) An abbreviated Mindfulness-based Intervention for Seniors (MBIS). The abbreviated version of the MBIS is well suited for seniors due to its length, its fewer requirements, and due to the fact that it can be administered by instructors that are not required to undergo lengthy and expensive training; 2) Cognitive Behavioral Therapy (CBT). 3) control group of care as usual. Both, the MBIS and the CBT intervention sessions, were 30 minutes long and took place in a designated room and on a weekly basis for 8 weeks throughout January and February 2019. The interventions were administered by an instructor with two years of experience practicing mindfulness meditation. Immediately after completing the course, all participants completed, for the second time, the questionnaire battery. 
Intervention Protocols:

MBIS - The MBIS course is based on the standard MBCT and MBSR courses (see Appendix 1 for the full intervention program). The course program was built using the principles of Holzel et al's (2011) model. Each session included practice (10-20 minutes), psycho-education (5-10 minutes) and/or sharing of experiences (3-10 minutes). In addition, all participants were asked to practice 10 minutes a day, in accordance to the exercise practiced during the session. Aside from the formal practice, participants were instructed to integrate attention activities in their daily activities, according to their choice. In accordance with Holzel et al.'s (2011) model, the course began with attention regulation and body awareness exercises and, later, other exercises were added that activate the processes of emotion regulation and change in perspective of the self.

CBT - The CBT course is based on the manual for CBT (abbreviated) therapists (Cully et al., 2008). The course was built of 8 sessions, 30 minutes each. (see Appendix 2 for full intervention program). Each session included psycho-education and a joint discussion (20 minutes), a diaphragmatic breathing exercise (5 minutes) and an explanation of the home exercise (5 minutes). The home exercise took 10 minutes, in accordance to the exercise practiced during the session.

Both interventions began at the seniors club about a week after the participants completed the questionnaires.

Questionnaires:

1. Anxiety - Measured via two questionnaires: 1) The Beck Anxiety Inventory (BAI) is a multiple-choice questionnaire that measures anxiety severity and is comprised of 21 items. Each item has four answer options, with scores ranging from 0 to 3 . Increasing levels of anxiety receive higher total questionnaire scores (total questionnaire scores range from 0 to 63 ). The BAI has high internal reliability ( $a=.92)$ and is validated (Beck et al., 1988); and 2) The Penn State Worry Questionnaire (PSWQ) is a multiple-choice questionnaire that measures symptoms of worry and is comprised of 16 items. Each item has five answer options, with scores ranging from 1 to 5 . Increasing levels of worry receive higher total questionnaire scores (total questionnaire scores range from 16 to 80 ). The PSWQ has high internal reliability (a $=.91$ ) and is validated (Meyer et al., 1990).

2. Depression - Measured via the Patient Health Questionnaire-9 (PHQ-9). The PHQ-9 is a multiple-choice questionnaire that measures symptoms of depression and is comprised of 9 items. Each item has four answer options, with scores ranging from 0-3. Increasing levels of depression receive higher total questionnaire scores. This questionnaire has high internal reliability $(a=.89)$ and is validated (Kroenke et al., 2001).

3. Attitudes Toward Seeking Mental Health Treatment - Measured via the Inventory of Attitudes Toward Seeking Mental Health Services (IASMHS). The IASMHS is comprised of 24 items, divided by three factors: Psychological Openness, Help Seeking Propensity, and Indifference to Stigma. Each item has five answer options, with scores ranging from 1-5. The higher the tendency to seek mental health treatment, the higher the total questionnaire score (total questionnaire scores range from 24-120). This questionnaire has high internal reliability $(a=.87)$ and is validated (Mackenzie et al., 2004).

\section{Results}

\section{Demographic Variables}

A One-Factor Analysis of Variance was conducted to compare the two intervention groups via the following variables: age, subjective age, years of education, socio-economic status, frequency of contact with grandchildren, and time spent socially. A $x^{2}$-test was also performed in an attempt to compare the two intervention groups via gender, living arrangement, type of residence and familial status (see Table 1). No significant differences, aside from years of education, were found between the two groups. A further analysis was conducted on this variable that made use of the Scheffe criterion for significance. This analysis found that the MBIS group displayed significantly fewer years of education than the control group $\left(\mathrm{F}_{(2,21)}=5.86, \mathrm{p}<.01\right)$. 
Table 1

Means (and SDs) and differences between groups in demographic variables

\begin{tabular}{|c|c|c|c|c|c|c|}
\hline & $\begin{array}{l}\text { MBIS } \\
(\mathrm{N}=8)\end{array}$ & $\begin{array}{l}\mathrm{CBT} \\
(\mathrm{N}=8)\end{array}$ & $\begin{array}{l}\text { Control } \\
(\mathrm{N}=8)\end{array}$ & $\begin{array}{l}\text { All Participants } \\
(\mathrm{N}=24)\end{array}$ & $\begin{array}{l}\text { Statistical } \\
\text { Parameter }\end{array}$ & $\mathrm{P}<$ \\
\hline Gender (number of women) & 6 & 8 & 8 & 22 & $x^{2}=4.36$ & - \\
\hline Age & $76.38(5.24)$ & $72(7.09)$ & $71(3.02)$ & $73.13(5.67)$ & $F=2.26$ & - \\
\hline Change in Subjective Age & $0.63(10.16)$ & $0.81(9.54)$ & $0(0)$ & $0.48(7.69)$ & $F<1$ & - \\
\hline Years of Education & $10.50(2.78)^{(-)}$ & $12.25(1.98)$ & $14.25(1.67)^{(-)}$ & $12.33(2.62)$ & $F=5.86$ & .01 \\
\hline SES & $3.38(0.74)$ & $3.38(0.74)$ & $2.88(0.84)$ & $3.21(0.78)$ & $F=1.16$ & - \\
\hline Contact with Grandchildren & $5.13(0.64)$ & $4.38(1.19)$ & $4(1.6)$ & $4.5(1.25)$ & $F=1.79$ & - \\
\hline Time Spent Socially & $4.88(0.35)$ & $4.75(0.46)$ & $4.75(0.7)$ & $4.79(0.51)$ & $\mathrm{F}<1$ & - \\
\hline
\end{tabular}

\section{Correlations Between Research Measures at Time 1 and the Demographic Variables}

In an attempt to examine correlations between the research measures at Time 1 and the demographic variables, a Pearson correlation was calculated (see Table 2). A moderately negative and significant correlation was found between time spent socially and levels of depression ( $r=$ $-.53, p<.05)$ and levels of anxiety $(r=-.59, p<.01)$. In other words, more time spent socially correlated with lower levels of depression and anxiety. Likewise, a moderately positive and significant correlation was found between levels of worry and levels of anxiety $(r=5.23$, $p<.01)$ and depression $(r=.6, p<.01)$. In other words, higher levels of worry correlated with higher levels of anxiety and depression. A strong positive correlation between anxiety and depression was also found $(r-=.72, p<.01)$. In other words, higher levels of anxiety correlated with higher levels of depression. Finally, a moderately negative and significant correlation was found between attitudes towards seeking mental health treatment and frequency of contact with grandchildren $(r=-.5, p<.05)$. In other words, more frequent contact with grandchildren correlated with less negative attitudes towards seeking mental health treatment.

Table 2

Correlations between research variables at Time 1 and the demographic variables.

\begin{tabular}{|c|c|c|c|c|c|c|c|c|c|}
\hline & Age & $\begin{array}{l}\text { Years of } \\
\text { Education }\end{array}$ & SES & $\begin{array}{l}\text { Frequency of } \\
\text { Contact with } \\
\text { Grandchildren }\end{array}$ & $\begin{array}{l}\text { Time } \\
\text { Spent } \\
\text { Socially }\end{array}$ & $\begin{array}{l}\text { Attitudes - } \\
\text { Seeking MH } \\
\text { treatment T1 }\end{array}$ & $\begin{array}{l}\text { Depression } \\
\text { Time } 1\end{array}$ & $\begin{array}{l}\text { Anxiety } \\
\text { Time } 1\end{array}$ & $\begin{array}{l}\text { Worry } \\
\text { Time } \\
1\end{array}$ \\
\hline Age & 1 & -0.296 & -0.114 & 0.267 & -0.051 & -0.259 & -0.184 & 0.053 & -0.179 \\
\hline Years of Education & & 1 & -0.228 & -0.213 & 0.25 & -0.019 & -0.306 & -0.158 & -0.181 \\
\hline SES & & & 1 & -0.067 & 0.005 & 0.222 & -0.233 & $-.556 \star \star$ & -0.173 \\
\hline $\begin{array}{l}\text { Freq'-Contact with } \\
\text { Grandchildren }\end{array}$ & & & & 1 & 0.034 & $-.502 *$ & 0.067 & 0.118 & -0.083 \\
\hline $\begin{array}{l}\text { Time Spent } \\
\text { Socially }\end{array}$ & & & & & 1 & 0.024 & $-.532 \star \star$ & $-.586 \star \star$ & -0.189 \\
\hline $\begin{array}{l}\text { Attitudes-Seeking } \\
\text { MH treatment Time } \\
1\end{array}$ & & & & & & 1 & -0.255 & -0.222 & -0.09 \\
\hline Depression, Time 1 & & & & & & & 1 & $.722^{\star \star}$ & $.600 * *$ \\
\hline Anxiety, Time 1 & & & & & & & & 1 & $.523^{\star *}$ \\
\hline Worry, Time 1 & & & & & & & & & 1 \\
\hline
\end{tabular}


A Mixed-Design repeated-measures ANOVA was conducted in an attempt to examine emotional distress and attitudes towards seeking mental health treatment as a function of time (before/after) as a within-subject variable and type of intervention (MBIS/CBT/control) as a betweensubject variable (see Table 3a for means and SD). A borderline significant main effect was found for time in the anxiety measure (BAI). In other words, there was a decrease in anxiety levels before and after the intervention for all participants $\left(F_{(1,21)}=3.22, p<.09, n^{2}{ }_{p}=0.13\right)$. In contrast to the research hypothesis, no interaction was found between time and group. However, in accordance with the a-priori hypotheses, a follow-up analysis that compared the CBT group and the other two groups in their anxiety measures showed a borderline significant effect $\left(F_{(1,21)}=3.63, p<.08, n_{p}^{2}=0.15\right)$. In other words, the CBT group showed more of a decrease in anxiety levels than did the MBIS and control groups (see Figure 1 and Table $3 b$ ). Regarding the worry measure (PSWQ) and in accordance with the research hypothesis, a main effect was found for time $\left(F_{(1,21)}=4.93\right.$, $\left.p<.04\right)$ such, that levels of worry decreased on average for all participants. Also, for this measure, no interaction was found between time and group, in contrast to the research hypothesis. However, in accordance with the a-priori hypotheses, a follow-up analysis that compared the MBIS group and the other two groups showed a significant effect $\left(F_{(1,21)}=4.38\right.$, $\left.p<.05\right)$. In other words, the MBIS group showed more of a decrease in worry levels than did the CBT and control groups.

Lastly, and in contrast to the research hypothesis, no effects were found for the measure of depression (PHQ-9). Regarding attitudes towards seeking mental health treatment (IASMHS), a main effect for time was found $\left(F_{(1,21)}=14 . .07, p<.01\right)$ such, that there was an improvement on average for all participants in their attitudes towards seeking mental health treatment. Most importantly, a significant interaction was found between time and group with a moderate effect size $\left(F_{(1,21)}=4.57, p<.05, n^{2}{ }_{p}=0.3\right)$. A follow-up analysis showed a significant difference between the improvement in attitudes towards seeking mental health treatment in the MBIS and CBT group and the control group $\left(F_{(1,21)}=9.1\right.$, $\mathrm{p}<.01)$. In other words, all participants in the intervention groups showed an increase in their attitudes towards seeking mental health treatment after the intervention, in contrast to the control group participants, who showed no improvement at all (see Figure 2 and Table $3 \mathrm{~b}$ ).

Table 3a

Means (and SDs) for IASMHS, BAI, PSWQ, PHQ-9

\begin{tabular}{|c|c|c|c|c|c|c|c|c|}
\hline & & Before & (Time 1) & & & After & (Time 2) & \\
\hline & $\begin{array}{l}\text { MBIS } \\
(\mathrm{N}=8)\end{array}$ & $\begin{array}{l}\text { CBT } \\
(\mathrm{N}=8)\end{array}$ & $\begin{array}{l}\text { Control } \\
(\mathrm{N}=8)\end{array}$ & $\begin{array}{l}\text { All } \\
\text { Participants } \\
(\mathrm{N}=24)\end{array}$ & $\begin{array}{l}\text { MBIS } \\
(\mathrm{N}=8)\end{array}$ & $\begin{array}{l}\text { CBT } \\
(\mathrm{N}=8)\end{array}$ & $\begin{array}{l}\text { Control } \\
(\mathrm{N}=8)\end{array}$ & $\begin{array}{l}\text { All } \\
\text { Participants } \\
(\mathrm{N}=24)\end{array}$ \\
\hline IASMHS & $79.63(7.54)$ & $84.5(8.91)$ & $84.38(6.63)$ & $82.83(7.76)$ & $85.13(9.99)$ & $90.38(9.7)$ & $83.88(7.47)$ & $86.46(9.18)$ \\
\hline $\mathrm{BAl}$ & $9.25(7.29)$ & $13.63(5.55)$ & $13.25(16.8)$ & $12.04(10.75)$ & $9.25(6.5)$ & $10.25(5.75)$ & $11.13(13.75)$ & $10.21(9)$ \\
\hline PSWQ & $45.13(11.9)$ & $46(11.61)$ & $44.25(12.44)$ & $45.13(11.48)$ & $40.75(10.77)$ & $45.25(11.13)$ & $43.75(11.85)$ & $43.25(10.93)$ \\
\hline PHQ-9 & $5.75(3.45)$ & $7.13(5.19)$ & $6(6.23)$ & $6.29(4.9)$ & $5.38(3.78)$ & $5.25(4.56)$ & $6.25(5.55)$ & $5.63(4.5)$ \\
\hline
\end{tabular}

Table 3b

Effects for IASMHS, BAI, PSWQ, PHQ-9

\begin{tabular}{|c|c|c|c|c|c|c|}
\hline & Effects & Meaning & $d f$ & $F$ & $\mathbf{p}<$ & $n_{p}^{2}$ \\
\hline \multirow[t]{3}{*}{ IASMHS } & Time & $\begin{array}{l}\text { The attitudes towards seeking mental health treatment measure was higher } \\
\text { at time } 2 \text { than at time } 1 \text { for all groups }\end{array}$ & 1,21 & 14.07 & .01 & .4 \\
\hline & $\begin{array}{l}\text { Time } x \\
\text { Group }\end{array}$ & & & 4.57 & .05 & .3 \\
\hline & Contrast & $\begin{array}{l}\text { The attitudes towards seeking mental health treatment measure was higher } \\
\text { in the MBIS and CBT groups than in the control group at time } 1 \text { and time } 2\end{array}$ & & 9.1 & .01 & .3 \\
\hline \multirow[t]{2}{*}{ BAl } & Time & The anxiety measure was lower at time 2 than at time 1 for all groups & 1,121 & 3.22 & .09 & .13 \\
\hline & Contrast & $\begin{array}{l}\text { The anxiety measure was lower in the CBT and control groups than in the } \\
\text { MBIS group at time } 1 \text { and time } 2\end{array}$ & & 3.63 & .08 & .15 \\
\hline \multirow[t]{2}{*}{ PSWQ } & Time & The worry measure was lower at time 2 than at time 1 for all groups & 1,21 & 4.93 & .04 & .19 \\
\hline & Contrast & $\begin{array}{l}\text { The worry measure was lower in the MBIS group than in the CBT and control } \\
\text { groups }\end{array}$ & & 4.38 & .05 & .17 \\
\hline PHQ-9 & $\begin{array}{l}\text { All } \\
\text { Effects }\end{array}$ & & 1,21 & $<1.11$ & $\begin{array}{l}\text { Not } \\
\text { Measured }\end{array}$ & \\
\hline
\end{tabular}




\section{Analysis of Measures Before and After the Intervention}

In an attempt to analyze the research measures before and after the intervention, Pearson correlations were calculated (see Table 4). A moderately positive and significant correlation was found between change in subjective age and years of education ( $r=.47$, $p<.05)$ such, that the fewer the years of education, the bigger the difference in subjective age from time 1 to time 2 and the younger the perceived age from time 1 to time 2 . In other words, the less educated the elderly participant, the younger he/she reported feeling after the intervention. In addition, a moderately positive and significant correlation was found between change in worry and years of education ( $r=.41, p<.05)$. In other words, more years of education were correlated with a bigger difference in the worry measure from time 1 to time 2 . Further, a moderately negative and significant correlation was found between change in attitudes towards seeking mental health treatment and years of education ( $r=-.43$, $p<.05$ ). In other words, the fewer the years of education, the more the attitudes towards seeking mental health treatment improved from time 1 to time 2. As previously stated, a significant difference in years of education was found between the groups. This considered, the aforementioned findings will be further discussed in the discussion section of this paper. Lastly, a moderately negative and significant correlation was found between change in attitudes towards seeking mental health treatment and change in depression $(r=-.43, p<.05)$. In other words, the more the depression measure decreased from time 1 to time 2, the more positive the attitudes towards seeking mental health treatment became from time 1 to time 2.

Table 4

Analysis of measures before and after the intervention

\begin{tabular}{|c|c|c|c|c|c|c|c|c|c|c|}
\hline & $\begin{array}{l}\text { Change in } \\
\text { Subjective } \\
\text { Age }\end{array}$ & $\begin{array}{l}\text { Change } \\
\text { in } \\
\text { Anxiety }\end{array}$ & $\begin{array}{l}\text { Change } \\
\text { in } \\
\text { Worry }\end{array}$ & $\begin{array}{l}\text { Change in } \\
\text { Depression }\end{array}$ & $\begin{array}{l}\text { Change } \\
\text { in } \\
\text { Attitudes }\end{array}$ & Age & $\begin{array}{l}\text { Years of } \\
\text { Education }\end{array}$ & SES & $\begin{array}{l}\text { Frequency of } \\
\text { Contact with } \\
\text { Grandchildren }\end{array}$ & $\begin{array}{l}\text { Time } \\
\text { Spent } \\
\text { Socially }\end{array}$ \\
\hline $\begin{array}{l}\text { Change in } \\
\text { Subjective } \\
\text { Age }\end{array}$ & 1 & -0.111 & 0.067 & -0.091 & -0.111 & -0.1 & $.467^{\star}$ & -0.162 & -0.132 & 0.138 \\
\hline $\begin{array}{l}\text { Change in } \\
\text { Anxiety }\end{array}$ & & 1 & 0.275 & 0.156 & 0.065 & -0.002 & -0.044 & 0.27 & -0.223 & 0.237 \\
\hline $\begin{array}{l}\text { Change in } \\
\text { Worry }\end{array}$ & & & 1 & -0.003 & -0.147 & 0.038 & $.413^{*}$ & -0.085 & -0.332 & -0.027 \\
\hline $\begin{array}{l}\text { Change in } \\
\text { Depression }\end{array}$ & & & & 1 & $-.427 *$ & 0.2 & 0.334 & -0.066 & 0.056 & 0.211 \\
\hline $\begin{array}{l}\text { Change in } \\
\text { Attitudes }\end{array}$ & & & & & 1 & 0.295 & $-.426^{\star}$ & 0.339 & 0.01 & -0.03 \\
\hline Age & & & & & & 1 & -0.296 & -0.114 & 0.267 & -0.051 \\
\hline $\begin{array}{l}\text { Years of } \\
\text { Education }\end{array}$ & & & & & & & 1 & -0.228 & -0.213 & 0.25 \\
\hline SES & & & & & & & & 1 & -0.067 & 0.005 \\
\hline $\begin{array}{l}\text { Freq'- Contact } \\
\text { with } \\
\text { Grandchildren }\end{array}$ & & & & & & & & & 1 & 0.034 \\
\hline $\begin{array}{l}\text { Time Spent } \\
\text { Socially }\end{array}$ & & & & & & & & & & 1 \\
\hline
\end{tabular}

\section{Discussion}

The purpose of the current study was to examine the influence of a brief mindfulness intervention appropriated for elderly adults on measures of emotional distress and attitudes towards seeking mental health treatment amongst healthy seniors. The primary findings suggest that the MBIS intervention engenders a positive change in diminishing feelings of worry while the anxiety focused CBT intervention was successful in improving anxiety symptoms. No improvement was found in the depression measures. Regarding attitudes towards seeking mental health treatment, the MBIS and the CBT interventions, when compared to the control group, improved attitudes towards seeking mental health treatment.

First, it is important to relate to the years of education variable, that was found to have significant associations with change in subjective age, change in worry, and change in attitudes towards seeking mental health treatment as a result of the interventions. All these associations 
suggest that more years of education correlate with diminished mental health or perspectives on therapy. These correlations are surprising but are likely the result of between-group differences in this variable; years of education in the control group were higher than in any other group and significantly higher than in the MBIS group. In other words, the control group was particularly defined by it having the most years of education, alongside its other defining characteristic - undergoing no intervention. Because the difference in years of education between the control group and the CBT group was not significant, but interactions between the two intervention groups and worry and anxiety across time were significant, the intervention effect may be understood as a sustainable effect. In other words, it is less likely that few years of education in the MBIS group can explain the differences between the control group and the two intervention groups. Further, it is likely that the increased change in subjective age and the younger perception of oneself from time 1 to time 2 in the intervention groups, as well as the acceptance that characterizes MBIS, are results of the interventions and not of years of education.

Special attention is required to examine the modular influence of the MBIS and CBT interventions on the measures of worry and anxiety (the MBIS group only improved in the worry measure while the CBT group only improved in the anxiety measure), especially considering the many studies that suggest clear efficacy (via moderate-high effect sizes) for mindfulness-based interventions on anxiety and depression (as reflected in a comprehensive meta-analysis (Hofmann et al., 2010)). A possible explanation for this pattern of results is related to the therapeutic mechanism at the foundation of these interventions; while CBT is a symptom-focused intervention that aims to directly diminish the symptom over a short period of time (Fenn \& Byrne, 2013), mindfulness-based interventions focus on accepting the symptom and turning attention to it in an open and non-judgmental way (Kabat-Zinn, 2013). Interventions of this type are process focused and require more practice for more effective practice (Morgan et al., 2014). It is likely that the MBIS group showed no significant decrease in anxiety because it required very little practice. It is also important to note that the MBIS group performed their homework assignments very partially. This further substantiates the aforementioned explanation. A non-judgmental focus on experience can explain the decrease in levels of worry in the MBIS group, as such focus is inherent to the actual exercise, in which the individual learns to introspect and accept with openness a range of experiences, including worry. In contrast to the research hypothesis, no significant decrease in levels of depression was found amongst the MBIS group. However, and in accordance with research literature (Krause \& Hayward, 2015), more time spent socially correlated with lower levels of depression and anxiety amongst the elderly participants at time 1. It is possible that due to the narrow scale utilized by the PHQ-9 questionnaire (0-27), and the fact that the population sample is not a clinical population, the participants received low scores on this measure (see Table 3a), which, statistically speaking, appears to have encouraged a "floor effect," and diminished the probability of a significant effect (of improvement) after the intervention.

In both intervention groups, attitudes towards seeking mental health treatment were more positive after the manipulation. One can assume that this positive change in both groups is due to the fact that both interventions incorporated an open and non-judgmental discussion on negative emotions. Therefore, it is possible that the stigma associated with mental health treatment was diminished among the intervention participants. Likewise, it is likely that because the administrator was a student of clinical psychology (and presented him/herself that way), the relationship with him contributed to an improvement in the participants' perception of psychologists - a factor that is significant in improving attitudes towards seeking mental health treatment (Kessler et al., 2015). As stated earlier, as a result of the low scores in the depression measure alongside the narrow scale used in the questionnaire that measure depression, levels of depression did not decrease significantly. Even so, a correlation was found between a decrease in levels of depression and improvement in attitudes towards seeking mental health treatment. Considering the positive influence of mindfulness practice on depression has been replicated many times (Geiger et al., 2016), it may be useful to examine if attitudes towards seeking mental health treatment are influenced by mindfulness practice, mediated by levels of depression, if positive attitudes towards seeking mental health treatment diminish levels of depression or if the influence between these variables is reciprocal. An interesting finding in this study is that a higher frequency of contact with grandchildren was associated with negative attitudes towards seeking mental health treatment. In an attempt to understand this finding, it can by hypothesized that more frequent contact with grandchildren is associated with better mental health (Drew \& Silverstein), which minimizes the need for seeking out mental health treatment, or thinking about it.

The current study has a number of important limitations that have not been discussed thus far. First, a small number of participants participated in this study, affecting the statistical strength of the data analyses. Many efforts were made to encourage participation and prevent attrition. For example, group and personal reminders were sent and alternative session dates were offered if original session date meant limited participation. Further research, as in this research, should maintain the small size of the different groups as to maintain the efficacy of these interventions for older adults, but the number of groups should be increased, as to increase the statistical strength of the analyses. Second, the enrichment room at the community center did not act as a sterile or ideal environment, and was exposed to external noise and disturbances that possibly distracted or disturbed the participants. In addition, the personal limitations of the participants, associated with their age (e.g. loss of partial hearing, attention or reading difficulties) made it difficult for the participants to absorb some of the content, or engage in practice and learning. These limitations likely weakened the various effect sizes. In order to ease the participants out of excessive research tasks/procedures and avoid attrition as best as possible, the researchers of this study acted with leniency with regards to homework follow-up. Further, this study did not measure mindfulness via a mindfulness questionnaire, meaning there was no manipulation 
check performed in this study. These leniencies encouraged participants to continue participation in the course but weakened the intervention. Third, this study shortened the session length in the MBIS intervention in an attempt to lessen the intensiveness of the course without harming the essential features of the intervention - appropriating the course for elderly participants. However, elderly individuals benefit greatly from consistent and highly frequent practice and, therefore, it would be interesting to examine the efficacy of a research design that incorporates home assignments performed on a group level. Home assignments performed within a group should encourage motivation and more frequent performance (of home assignments) and, therefore, increase practice time and better implementation of the intervention (Morgan et al., 2014). Lastly, while this study examined independent seniors that function in an urban community, 22 of the 24 participants were women. This statistic suggests that the study findings largely reflect women.

We encourage future research to incorporate an additional measurement time, 6 months post time 2. This would help us better understand how well the reported changes are internalized (Mather et al., 2010). We hypothesize that with time, the differences between the intervention groups and the control group would maintain themselves and, even, strengthen, especially if the participants will continue to independently practice mindfulness up until the third measurement.

In summary, a brief mindfulness intervention diminished levels of worry amongst elderly participants, as has been found in earlier studies (Delgado et al., 2010). In addition, to the best of our knowledge, this is the first study to suggest that a mindfulness intervention improves attitudes towards seeking mental health treatment amongst the elderly. These findings have direct implications for the quality of life and wellbeing of seniors, especially since mindfulness exercises can be practiced at any time, do not require accessories, and are essentially independent of one's physical state. Further, it is likely that as a result of mindfulness practice, more seniors will allow themselves to utilize mental health services. It is important to note, however, that the mindfulness intervention did not diminish anxiety, and, likely due to a "floor effect", did not significantly improve measures of depression. The current study encourages mindfulness-based interventions for seniors (MBIS), which can be taught in group settings, with low cost, and at community centers or at public health clinics.

\section{Declarations}

\section{Compliance with Ethical Standards:}

- Research involving Human Participants and/or Animals: We confirm that the study was approved by the institutional and Helsinki ethics committee (Ruppin IRB and Beer-Yaakov hospital) and certify that the study was performed in accordance with the ethical standards as laid down in the 1964 Declaration of Helsinki and its later amendments or comparable ethical standards. Participants received explanation about the study and signed informed consent before committing to the study.

\section{Funding:}

- The authors did not receive support from any organization for the submitted work.

- No funding was received to assist with the preparation of this manuscript.

- No funding was received for conducting this study.

- No funds, grants, or other support was received.

\section{Conflicts of Interest / Competing Interests:}

- The authors have no relevant financial or non-financial interests to disclose.

- The authors have no conflicts of interest to declare that are relevant to the content of this article.

- All authors certify that they have no affiliations with or involvement in any organization or entity with any financial interest or nonfinancial interest in the subject matter or materials discussed in this manuscript.

- The authors have no financial or proprietary interests in any material discussed in this article.

\section{References}

1. Beck, A. T., Epstein, N., Brown, G., \& Steer, R. A. (1988). An inventory for measuring clinical anxiety: psychometric properties. Journal of consulting and clinical psychology, 56(6), 893.

2. Buysse, D. J., Germain, A., Moul, D. E., Franzen, P. L., Brar, L. K., Fletcher, M. E., ... \& Monk, T. H. (2011). Efficacy of brief behavioral treatment for chronic insomnia in older adults. Archives of internal medicine, 171(10), 887-895.

3. Carmody, J., \& Baer, R. A. (2009). How long does a mindfulness-based stress reduction program need to be? A review of class contact hours and effect sizes for psychological distress. Journal of Clinical Psychology, 65, 627-638

Page $10 / 13$ 
4. Chiesa, A., \& Serretti, A. (2009). Mindfulness-based stress reduction for stress management in healthy people: a review and meta-analysis. The journal of alternative and complementary medicine, 15(5), 593-600.

5. Conner, K. O., Copeland, V. C., Grote, N. K., Koeske, G., Rosen, D., Reynolds III, C. F., \& Brown, C. (2010). Mental health treatment seeking among older adults with depression: the impact of stigma and race. The American Journal of Geriatric Psychiatry, 18(6), 531-543.

6. Cully, J. A., \& Teten, A. L. (2008). A therapist's guide to brief cognitive behavioral therapy. Houston: Department of Veterans Affairs South Central MIRECC.

7. Delgado, L. C., Guerra, P., Perakakis, P., Vera, M. N., del Paso, G. R., \& Vila, J. (2010). Treating chronic worry: Psychological and physiological effects of a training programme based on mindfulness. Behaviour research and therapy, 48(9), 873-882.

8. Drew, L. M., \& Silverstein, M. (2007). Grandparents' psychological well-being after loss of contact with their grandchildren. Journal of Family Psychology, 21(3), 372.

9. Fenn, K., \& Byrne, M. (2013). The key principles of cognitive behavioral therapy. InnovAiT, 6(9), 579-585.

10. Foulk, M. A., Ingersoll-Dayton, B., Kavanagh, J., Robinson, E., \& Kales, H. C. (2014). Mindfulness-based cognitive therapy with older adults: an exploratory study. Journal of gerontological social work, 57(5), 498-520.

11. Garroway, A.M., \& Rybarczyk, B. (2015). Aging, chronic disease and the biopsychosocial model. In B. T. Mast \& P. A. Lichtenberg (Eds.), Handbook of Clinical Geropsychology. Washington, DC: American Psychological Association.

12. Geiger, P. J., Boggero, I. A., Brake, C. A., Caldera, C. A., Combs, H. L., Peters, J. R., \& Baer, R. A. (2016). Mindfulness-based interventions for older adults: a review of the effects on physical and emotional well-being. Mindfulness, 7(2), 296-307.

13. Goffman E. Stigma. Englewood Cliffs, NJ: Prentice Hall; 1963.

14. Grossman, P., Niemann, L., Schmidt, S., \& Walach, H. (2004). Mindfulness-based stress reduction and health benefits: A meta-analysis. Journal of psychosomatic research, 57(1), 35-43.

15. Gu, J., Strauss, C., Bond, R., \& Cavanagh, K. (2015). How do mindfulness-based cognitive therapy and mindfulness-based stress reduction improve mental health and wellbeing? A systematic review and meta-analysis of mediation studies. Clinical psychology review, $37,1-12$.

16. Helmes, E., \& Ward, B. G. (2017). Mindfulness-based cognitive therapy for anxiety symptoms in older adults in residential care. Aging \& mental health, 21(3), 272-278.

17. Hofmann, S. G., Sawyer, A. T., Witt, A. A., \& Oh, D. (2010). The effect of mindfulness-based therapy on anxiety and depression: A metaanalytic review. Journal of consulting and clinical psychology, 78(2), 169.

18. Hölzel, B. K., Lazar, S. W., Gard, T., Schuman-Olivier, Z., Vago, D. R., \& Ott, U. (2011). How does mindfulness meditation work? Proposing mechanisms of action from a conceptual and neural perspective. Perspectives on psychological science, 6(6), 537-559.

19. Jorm, A. F. (2000). Does old age reduce the risk of anxiety and depression? A review of epidemiological studies across the adult life span. Psychological medicine, 30(1), 11-22.

20. Kabat-Zinn, J. (2013). Full catastrophe living, revised edition: how to cope with stress, pain and illness using mindfulness meditation. Hachette UK.

21. Kessler, E. M., Agines, S., \& Bowen, C. E. (2015). Attitudes towards seeking mental health services among older adults: Personal and contextual correlates. Aging \& mental health, 19(2), 182-191.

22. Kitzmüller, G., Clancy, A., Vaismoradi, M., Wegener, C., \& Bondas, T. (2018). "Trapped in an Empty Waiting Room"-The Existential Human Core of Loneliness in Old Age: A Meta-Synthesis. Qualitative health research, 28(2), 213-230.

23. Krause, N., \& Hayward, R. D. (2015). Social perspectives: Support, social relations, and well-being. In P. A. Lichtenberg, B. T. Mast, B. D. Carpenter, \& J. Loebach Wetherell (Eds.), APA handbooks in psychology. APA handbook of clinical geropsychology, Vol. 1. History and status of the field and perspectives on aging (pp. 259-299). Washington, DC, US: American Psychological Association.

24. Kroenke, K., Spitzer, R. L., \& Williams, J. B. (2001). The PHQ-9: validity of a brief depression severity measure. Journal of general internal medicine, 16(9), 606-613.

25. Lenze, E. J., Hickman, S., Hershey, T., Wendleton, L., Ly, K., Dixon, D., ... \& Wetherell, J. L. (2014). Mindfulness-based stress reduction for older adults with worry symptoms and co-occurring cognitive dysfunction. International journal of geriatric psychiatry, 29(10), 991-1000.

26. Mackenzie, C. S., Knox, V. J., Gekoski, W. L., \& Macaulay, H. L. (2004). An Adaptation and Extension of the Attitudes Toward Seeking Professional Psychological Help Scale 1. Journal of Applied Social Psychology, 34(11), 2410-2433.

27. Marjani, M. A. (2017). Factors Predictive of Participant Attrition in Mindfulness-Based Stress Reduction (Doctoral dissertation, Alliant International University).

28. Mathew, K. L., Whitford, H. S., Kenny, M. A., \& Denson, L. A. (2010). The long-term effects of mindfulness-based cognitive therapy as a relapse prevention treatment for major depressive disorder. Behavioural and Cognitive Psychotherapy, 38(5), 561-576. 
29. Meyer, T. J., Miller, M. L., Metzger, R. L., \& Borkovec, T. D. (1990). Development and validation of the penn state worry questionnaire. Behaviour research and therapy, 28(6), 487-495.

30. Morgan, L. P., Graham, J. R., Hayes-Skelton, S. A., Orsillo, S. M., \& Roemer, L. (2014). Relationships between amount of post-intervention mindfulness practice and follow-up outcome variables in an acceptance-based behavior therapy for Generalized Anxiety Disorder: The importance of informal practice. Journal of Contextual Behavioral Science, 3(3), 173-178.

31. Nam, S., \& Toneatto, T. (2016). The influence of attrition in evaluating the efficacy and effectiveness of mindfulness-based interventions. International Journal of Mental Health and Addiction, 14(6), 969-981.

32. Neimeyer, R. A., \& Holland, J. M. (2015). Bereavement in later life: Theory, assessment and intervention. In B. T. Mast \& P. A. Lichtenberg (Eds.), Handbook of Clinical Geropsychology. Washington, DC: American Psychological Association.

33. Noice, H., Noice, T., \& Staines, G. (2004). A short-term intervention to enhance cognitive and affective functioning in older adults. Journal of aging and health, 16(4), 562-585.

34. Rodda, J., Walker, Z., \& Carter, J. (2011). Depression in older adults. BMJ-British Medical Journal, $343(8)$, d5219.

35. Reynolds, K., Pietrzak, R. H., El-Gabalawy, R., Mackenzie, C. S., \& Sareen, J. (2015). Prevalence of psychiatric disorders in US older adults: findings from a nationally representative survey. World Psychiatry, 14(1), 74-81.

36. Satre, D. D., Knight, B. G., \& David, S. (2006). Cognitive-behavioral interventions with older adults: Integrating clinical and gerontological research. Professional Psychology: research and practice, 37(5), 489.

37. Segal, Z. V., Williams, J. M. G., \& Teasdale, J. D. (2002). Mindfulness-Based Cognitive Therapy for Depression: A new approach to preventing relapse. London, UK: Guilford Press.

38. Shapiro, S. L., Carlson, L. E., Astin, J. A., \& Freedman, B. (2006). Mechanisms of mindfulness. Journal of clinical psychology, 62(3), 373386.

39. Skelton, D.A., \& Muhaidat, J. (2015). Mobility in Later Life. In B. T. Mast \& P. A. Lichtenberg (Eds.), Handbook of Clinical Geropsychology. Washington, DC: American Psychological Association.

40. Young, L. A., \& Baime, M. J. (2010). Mindfulness-based stress reduction: Effect on emotional distress in older adults. Complementary health practice review, 15(2), 59-64.

\section{Figures}

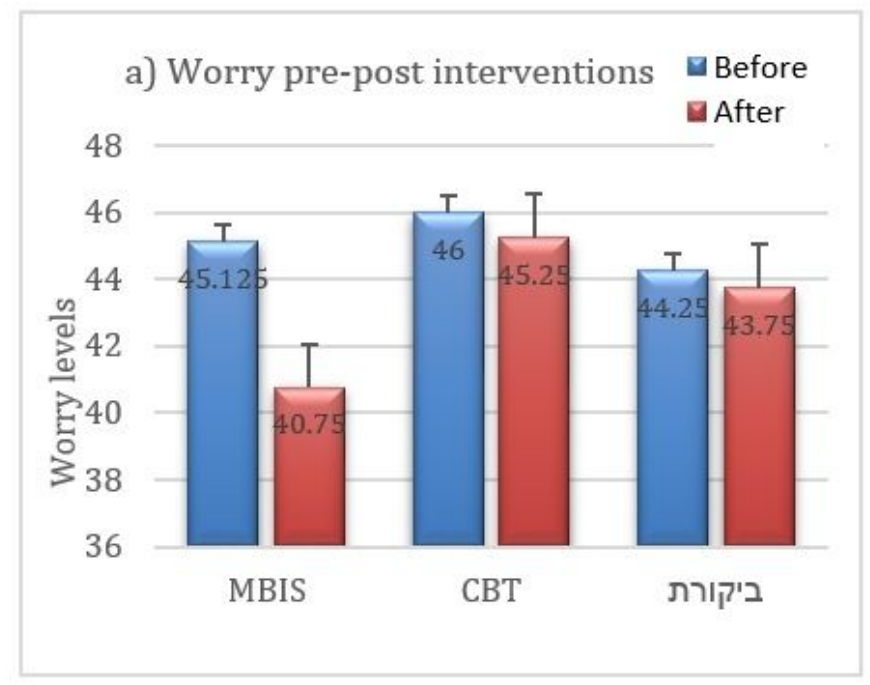

MBIS

CBT Control
Group

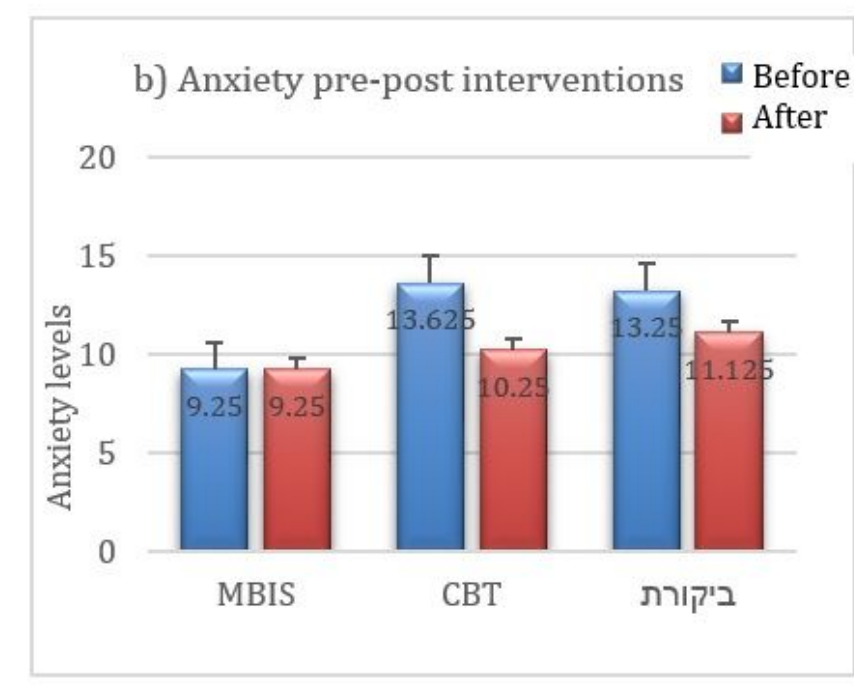

MBIS

CBT

Control

\section{Figure 1}

a) worry and b) anxiety levels before and after the interventions 


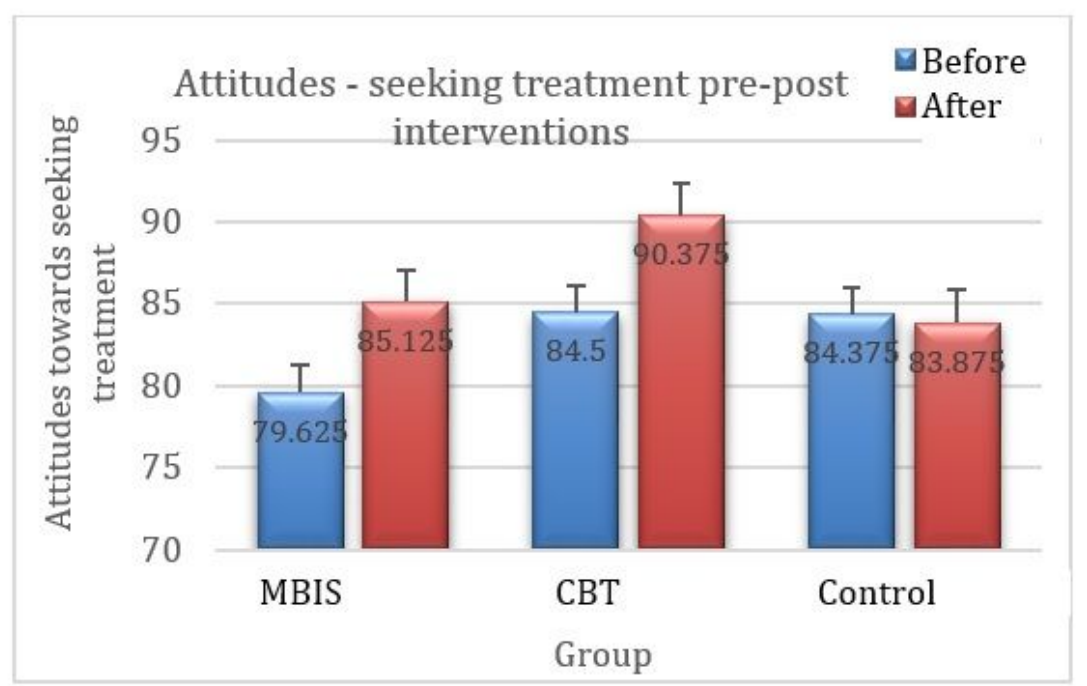

\section{Figure 2}

Attitudes towards seeking mental health treatment before and after the intervention

\section{Supplementary Files}

This is a list of supplementary files associated with this preprint. Click to download.

- MindfulnesscomparedtoCBTeffectsappendices.docx 